\title{
PROXIMAL AORTIC DISSECTION WITH CORONARY MALPERFUSION: PRESENTATION, MANAGEMENT, AND OUTCOME
}

\author{
Eugenio Neri, $\mathrm{MD}^{\mathrm{a}}$ \\ Thomas Toscano, MD, $\mathrm{PhD}^{\mathrm{a}}$ \\ Ugo Papalia, $\mathrm{MD}^{\mathrm{b}}$ \\ Giacomo Frati, MD \\ Massimo Massetti, MD \\ Gianni Capannini, MD $^{\mathrm{a}}$ \\ Enrico Tucci, MD \\ Dimitri Buklas, MD \\ Luigi Muzzi, MDa \\ Luca Oricchio, $\mathrm{MD}^{\mathrm{a}}$ \\ Carlo Sassi, MD
}

Background: Acute myocardial ischemia and infarction due to retrograde dissection of the aortic root reaching the coronary ostia is a potentially fatal condition. Surgical treatment of these patients relies on the re-establishment of an adequate coronary blood flow and on the rescue of jeopardized myocardium. This article reports the results of a selected group of 24 patients with type A acute aortic dissection and coronary artery dissection. We review our experience and illustrate our approach to this condition, which evolved over a 15-year period.

Methods: Between July 1985 and March 2000, 24 patients from a total of 211 $(11.3 \%)$ treated for acute type A aortic dissection had dissection of at least one of the coronary ostia. There were 14 men and 10 women. The mean age was 65.5 years (median 61.7; range $41-78$ years). The right coronary artery was involved in 11 patients, the left in 4 patients, and both coronary arteries in 9 patients. At admission, 16 patients had Q waves $(66 \%)$, inferior in 6 $(25 \%)$ and anterior, lateral, septal, or posterior in $10(41 \%)$. All procedures were done on an emergency basis within 10 hours (median 4 hours) after initial chest pain and within 2 hours after the patient's arrival.

Results: Hospital mortality was $20 \%$ (5 patients); 3 patients could not be weaned from cardiopulmonary bypass and died intraoperatively, and 2 patients died postoperatively of low cardiac output.

Conclusions: As illustrated in this study, direct coronary repair is a safe alternative to bypass grafting. Aggressive myocardial resuscitation together with early operation is a key factor in the management of these patients. ( $\mathrm{J}$ Thorac Cardiovasc Surg 2001;121:552-60)
$\mathrm{R}$ etrograde dissection of the aortic root reaching the coronary ostia was noted in $7 \%$ of necropsies according to Hirst, Jones, and Kime, ${ }^{1}$ and it is a relatively common clinical finding. ${ }^{2}$ In acute type $\mathrm{A}$ aortic dissection, acute myocardial ischemia and infarction due to this mechanism are severe complications, potentially leading to irreversible myocardial damage. Aortic dissection is not often considered a cause of myocardial malperfusion; thus, fatal accidents resulting from the thrombolytic treatment given to these patients are not uncommon. ${ }^{3,4}$

From the Istituto di Chirurgia Cardiovascolare ${ }^{\mathrm{a}}$ Università agli Studi di Siena, Unita' Operativa di Chirurgia dell' Aorta Toracica, Istituto di Istituto di Chirurgia del Cuore e Grossi Vasi, ${ }^{\text {b }}$ Università "La Sapienza," Rome, Italy.

Copyright (C) 2001 by The American Association for Thoracic Surgery

$0022-5223 / 2001 \$ 35.00+0 \quad \mathbf{1 2 / 1 / 1 1 2 5 3 4}$

doi: $10.1067 / \mathrm{mtc} .2001 .112534$
Surgical treatment of patients with acute dissection of the coronary arteries is challenging. Management of this condition should take into account the re-establishment of an adequate coronary blood flow and involves important issues such as postischemic myocardial salvage/restoration and postoperative treatment for low cardiac output.

The approach to coronary revascularization in these patients relies on various techniques that span from coronary artery bypass grafting to the strategies of repair of torn coronary vessels.

This article reports the results of a selected group of 24 patients with type A acute aortic dissection and coronary artery dissection. We review our experience and illustrate our approach to this condition, which evolved over a 15-year period.

\section{Patients and methods}

Patients. Between July 15, 1985, and March 20, 2000, 40 patients from a total of 211 (18.9\%) treated for acute type A aortic dissection in our institution had electrocardiographic 
Table I. Clinical characteristics of patients

\begin{tabular}{lrr}
\hline & No. & Percent \\
\hline Clinical background & & \\
Median age (y) & 65.5 & \\
Female & 10 & 41 \\
Hypertension & 24 & 100 \\
Marfan syndrome & 0 & 0 \\
History of CAD & 0 & 0 \\
Renal insufficiency & 1 & 4 \\
COPD & 3 & 12 \\
Clinical presentation & & \\
Chest pain & 24 & 100 \\
Stroke & 3 & 12 \\
Hypotension & 16 & 66 \\
Acute aortic regurgitation & 24 & 100 \\
Acute mitral regurgitation & 6 & 25 \\
Pericardial effusion* & 24 & 100 \\
Cardiac tamponade $\dagger$ & 4 & 16 \\
Cardiac arrest-fibrillation & 3 & 12 \\
Atrial arrhythmias & 11 & 46 \\
Ventricular arrhythmias & 9 & 37 \\
Right bundle branch block & 7 & 29 \\
Left bundle branch block & 13 & 54 \\
Aortic rupture & 0 & 0 \\
Anterolateral ischemia & 12 & 50 \\
Inferior ischemia $\ddagger$ & 14 & 58 \\
Anterolateral Q waves & 10 & 41 \\
Inferior Q waves $\ddagger$ & 6 & 25 \\
\hline
\end{tabular}

$\overline{C A D \text {, Coronary artery disease; } C O P D \text {, chronic obstructive pulmonary dis- }}$ ease.

*Preoperative noninvasive diagnosis of pericardial effusion.

$\dagger$ Pericardial effusion with hemodynamic significance.

\#Electrocardiographic changes in inferior, inferoposterior, posterior, or inferolateral leads are defined as inferior.

signs of myocardial ischemia. Among these, 24 (11.3\%) had dissection of at least one of the coronary ostia, whereas in the remaining patients myocardial ischemia was attributable to chronic atherosclerotic coronary artery disease (CAD).

Clinical characteristics of patients with dissection of the coronary ostia are illustrated in Table I. There were 14 men and 10 women. The mean age of patients was 65.5 years (median 61.7; range 41-78 years). The right coronary artery was involved in 11 patients, the left in 4 patients, and both coronary arteries in 9 patients.

At admission, none of the patients was moribund. None required external chest compression for cardiopulmonary resuscitation, and all had hemodynamic instability, attributable to myocardial dysfunction, arrhythmias, acute aortic and mitral regurgitation, and cardiac tamponade. Sixteen patients $(66 \%)$ had marked hypotension. One or more episodes of cardiac arrest or ventricular fibrillation occurred before hospital arrival in 3 patients. None of the patients was unconscious at admission, although 3 patients had a preoperative stroke.

Preoperative electrocardiography revealed ST or T-wave abnormalities in all 24 patients; of these, $16(66 \%)$ had Q waves, inferior in $6(25 \%)$ and anterior, lateral, septal, or posterior in 10 $(41 \%)$. Preoperative echocardiograms revealed severe abnor-
Table II. Preoperative diagnostic evaluations

\begin{tabular}{lcc}
\hline Diagnostic evaluation & No. & Percent \\
\hline Chest radiography & 22 & 91 \\
Transthoracic echocardiography & 24 & 100 \\
Transesophageal echocardiography & 12 & 50 \\
Contrast computed tomographic scan & 22 & 22 \\
Coronary angiogram & 8 & 33 \\
\hline
\end{tabular}

Table III. Operations

\begin{tabular}{lrr}
\hline & No. & Percent \\
\hline Distal procedure & & \\
$\quad$ Ascending aorta replacement & 4 & 16 \\
Hemiarch replacement & 20 & 83 \\
Arch replacement & 0 & 0 \\
Proximal procedure & & \\
$\quad$ Aorto-aortic graft & 3 & 12 \\
$\quad$ Valve-sparing technique & 4 & 16 \\
Composite graft & 17 & 71 \\
Management of coronary artery lesions & & \\
Right coronary artery & & \\
$\quad$ CABG & 2 & 8 \\
$\quad$ Local repair & 8 & 33 \\
$\quad$ Patch repair & 7 & 29 \\
$\quad$ Short graft & 3 & 12 \\
Left coronary artery & & \\
CABG & 3 & 12 \\
$\quad$ Local repair & 3 & 12 \\
$\quad$ Patch repair & 3 & 12 \\
$\quad$ Short graft & 4 & 16 \\
\hline
\end{tabular}

$C A B G$, Coronary artery bypass grafting.

malities of segmental wall motion of both ventricles in 7 patients and of the left ventricle in 17. Mean preoperative left ventricular ejection fraction, calculated at echocardiography, was $31 \%$ (median $32 \%$; range $18 \%-44 \%$ ). Acute mitral regurgitation from papillary muscle dysfunction was present in 6 patients. Nine patients had frank pulmonary edema. Average peak preoperative creatine kinase MB (CK-MB) level was 58.7 IU/L (median 44 IU/L, range 19-250 IU/L).

Preoperative coronary angiography was performed in 8 of the 24 patients with coronary dissection, none of whom had chronic CAD. In patients who did not undergo angiography, the coronary arteries were evaluated for chronic CAD at operation by epicardial palpation and in some cases by probing the coronary orifices from within the opened ascending aorta. No sign of chronic CAD was found in these patients. Preoperative investigations are listed in Table II.

All procedures were done on an emergency basis within 10 hours (median 4 hours) after initial chest pain and within 2 hours after the patient's arrival. The operative techniques used are summarized in Table III. In all patients the repair was performed with an open technique with hypothermic circulatory arrest. Retrograde cerebral perfusion was used in $4(16.6 \%)$ patients. The left axillary artery was cannulated in $3(12.5 \%)$ patients. 

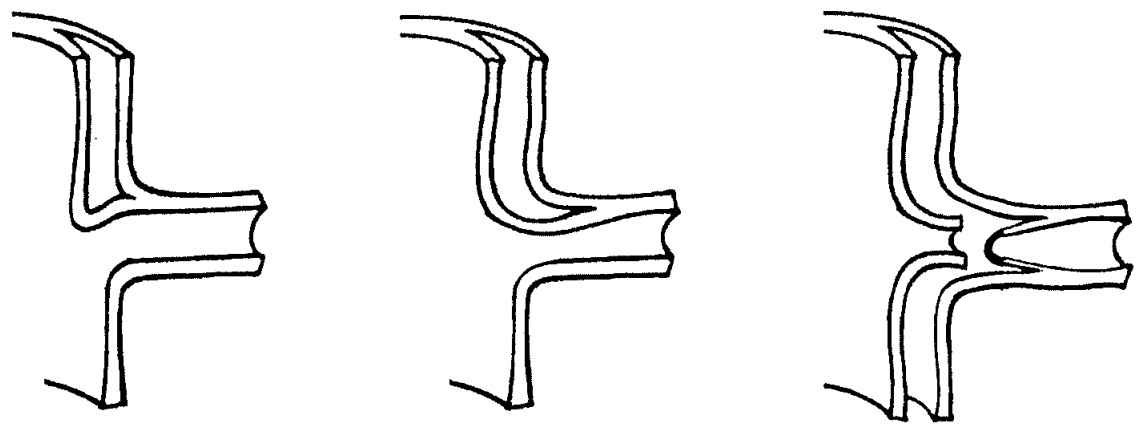

A
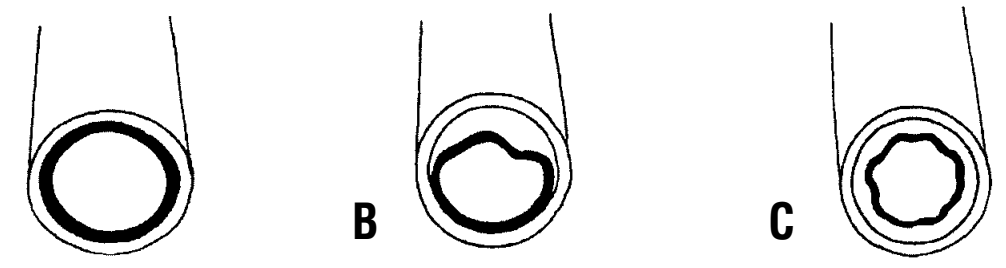

Fig 1. Three main types of coronary lesion due to proximal dissection: type A, ostial dissection (A); type B, dissection with a coronary false channel (B); type $C$, circumferential detachment with an inner cylinder intussusception $(\mathbf{C})$.

During the period 1985 to 1988 , the technique of myocardial management differed from that used later in the study. In the first $6(25 \%)$ patients, crystalloid cardioplegic solution was intermittently administered only at the end of the circulatory arrest period and controlled reperfusion was not used. Blood cardioplegic solution was administered retrogradely through the coronary sinus in 6 patients and retrogradely plus antegradely through the nondissected coronary ostium in 12 patients. Controlled reperfusion was administered antegradely in 6 patients and retrogradely in 12 patients. The mean period of cooling for these patients was 29 minutes, and mean circulatory arrest time was 21 minutes (range 12-44 minutes). The time for rewarming averaged 49 minutes. Mean cardiopulmonary bypass (CPB) time was 219 minutes (median 183 minutes; range 160-427 minutes).

Average peak postoperative CK-MB level was 77.3 IU/L (median $48 \mathrm{IU} / \mathrm{L}$, range 29-320 IU/L). Postoperative mean peak CK-MB level for patients who did not have a perioperative Q-wave myocardial infarction was $42 \mathrm{IU} / \mathrm{L}$ (median $38.5 \mathrm{IU} / \mathrm{L}$, range 29-73 IU/L) versus $95.0 \mathrm{IU} / \mathrm{L}$ (median 50 IU/L, range 32-320 IU/L) in patients who did have a perioperative Q-wave myocardial infarction.

In all patients, histologic examination of aortic tissue specimens revealed the typical features of cystic medial necrosis with mucoid degeneration (grade 3 or 4 medial degeneration). Histologic examination of the coronary arteries of patients who died after the operation and of the specimen of the coronary arteries resected during the operation did not demonstrate any degenerative changes.

Types of coronary ostial lesions. We differentiate among three main types of lesions (Fig 1): (1) type A, ostial dissec- tion; (2) type B, dissection with a coronary false channel; and (3) type $\mathrm{C}$, circumferential detachment with an inner cylinder intussusception.

Ostial dissection is defined as a disruption of the inner layer limited to the area of the coronary ostium. This kind of lesion may be not be associated with coronary malperfusion unless a local flap is created, obstructing flow with a trapdoor mechanism. In dissection with a coronary false channel, a dehiscence of the coronary artery is produced. Blood from the aortic false channel progresses into the coronary ostium, creating an extension of the false lumen into the coronary artery. In general, the false lumen is located in the upper aspect of the artery. Its extension along the length of the artery is variable and may involve the artery for several millimeters. The mechanism of coronary flow impairment has been attributed to the compression in diastole of the true lumen by the obstructing false channel.

In the third type, the dissection encircles the affected coronary ostium and may extend along the course of the left or right main coronary artery. In such cases, the affected ostium is totally dehisced from the true aortic lumen with intussusception of the inner wall cylinder into the outer coat of the respective coronary artery. Malperfusion in these cases is produced by direct obstruction of coronary blood flow.

In our series we have found 12 type A lesions ( 9 of the right and 3 of the left coronary artery), of which 4 were responsible for malperfusion. Type B lesions were found in 12 patients ( 8 of the right and 4 of the left coronary artery) and type C lesions in 9 ( 3 of the right and 6 of the left coronary artery). Lesions of both coronary ostia were found in 8 patients; in none of these did type $\mathrm{B}$ and type $\mathrm{C}$ lesions coexist. 


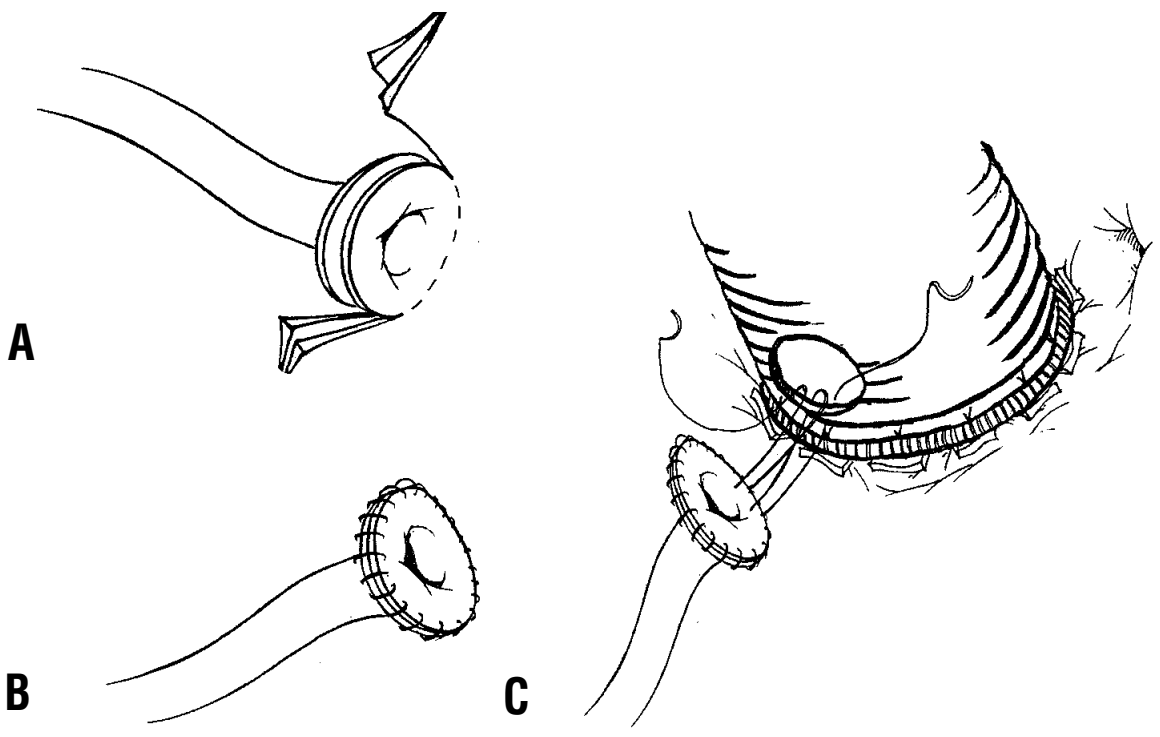

Fig 2. When the dissection reaches the ostium, without disrupting the coronary vessel (type A), the coronary ostium is excised in button form, with a 4-mm margin of the surrounding aortic wall (A). The dissected layers around the ostium are then conjoined with gelatin-resorcin-formalin glue and an over-and-over 6-0 suture (B). The ostial button then is anastomosed to the tube graft without torsion or tension (C).

Operative technique. All operations in this series (Table III) were performed through a median sternotomy. In all cases hypothermic circulatory arrest was a planned procedure to allow distal anastomosis by means of an open technique. In the present protocol, in use since 1988, the right atrium and the femoral artery with the best pulsation, or one of the axillary arteries, are cannulated. The coronary sinus is cannulated for retrograde cardioplegia. CPB is established, with cardiac indices of 2.0 to 2.5 $\mathrm{L} \cdot \mathrm{min}^{-1} \cdot \mathrm{m}^{-2}$, systemic cooling is initiated immediately, and the left ventricle is vented via the right superior pulmonary vein. As CPB is started, the ascending aorta is crossclamped in its midportion, a few centimeters above the sinotubular junction, and opened. The heart is covered with cold saline solution. Cold blood cardioplegic solution is administered either retrogradely via the coronary sinus at $250 \mathrm{~mL} / \mathrm{min}$ or retrogradely plus antegradely $(350 \mathrm{~mL} / \mathrm{min})$ through the nondissected coronary ostium, for a total of 4 minutes, with coronary sinus pressures nearing $40 \mathrm{~mm} \mathrm{Hg}$. The dose is repeated every 15 to 20 minutes during systemic cooling and rewarming. During the cooling period, the aorta is freed from the pulmonary artery and transected above the aortic commissures. The presence and the extent of the dissection, in relation to the coronary ostia, are then assessed. In the event that one or two coronary ostia are torn by proximal dissection, repair is accomplished after completion of the distal anastomosis.

By means of an open technique, the intimal tear is resected and the dissected layers of aorta are reapproximated with gelatin-resorcin-formalin glue at the site of the distal anastomosis. Systemic cooling is considered adequate for hypothermic circulatory arrest when the nasopharyngeal temperature has reached $20^{\circ} \mathrm{C}$ and the bladder temperature is below $28^{\circ} \mathrm{C}$.
The dissected aortic valve commissures are resuspended if the valve can be preserved, or else the valve is replaced with a composite graft conduit. Normothermic controlled reperfusion is administered either antegradely or retrogradely for 20 minutes after the completion of proximal repair, before crossclamp release. The heart is vented and assisted throughout the controlled reperfusion and at least for an additional 30 minutes after completion of controlled reperfusion.

Before any attempt at weaning from $\mathrm{CPB}$, a precise assessment of the regional contractility and of the extent of the myocardial damage is obtained with the aid of transesophageal echocardiography. The presence of ventricular arrhythmias may represent an expression of reperfusion injury and should lead to the continuance of CPB with the heart vented.

Techniques of coronary repair. The technique of repair depends on the type and the extent of the lesion and on which coronary artery is involved. If the dissection has reached the ostium without disrupting the coronary vessel (type A), the coronary ostium is repaired with a continuous 6-0 over-andover suture conjoining the dissected arterial layers, leaving the ostium in continuity with the aortic wall. In ostia completely surrounded by the dissection, or in the presence of extremely fragile tissues, we prefer to excise the ostium in button form with a 4-mm margin of the surrounding aortic wall (Fig 2). The dissected aortic layers of the ostial button are then conjoined with gelatin-resorcin-formalin glue and an over-and-over 6-0 suture: attention is paid to not put glue inside the layers of the coronary artery to avoid secondary stenosis. The ostial button then is anastomosed to the tube graft without torsion or tension. 


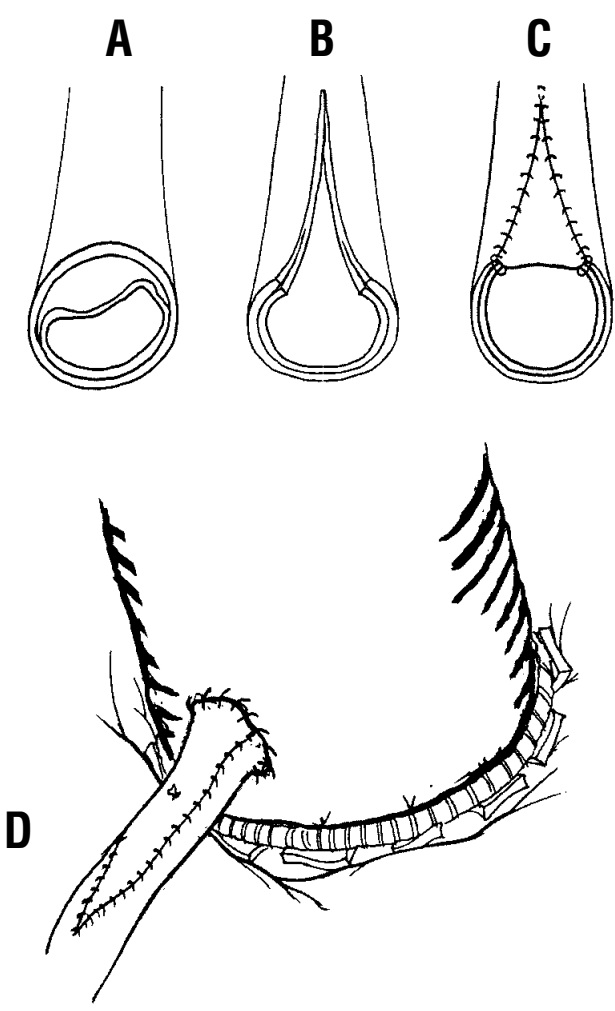

Fig 3. In the event of type B lesions (A), the coronary artery is incised longitudinally (B) and patch repair is performed with a continuous 7-0 polypropylene suture conjoining the dissected arterial layers and the patch $(\mathbf{C})$. The repaired artery is then anastomosed to the aortic graft (D).

In the event of dissection progressing beyond the ostium (type B-C), techniques of repair depend on the presence of intussusception and on the extent of the dissection.

The extent of the lesion is assessed by freeing the coronary artery, to a variable extent, along its course. In the case of left main coronary artery dissection, it may be necessary to divide the main pulmonary artery to visualize the bifurcation between the circumflex and left anterior descending arteries. The typical bluish aspect of dissection on the vessel surface indicates precisely the extent of the lesion.

In the absence of intussusception (type B), the coronary artery is incised longitudinally and patch repair is performed with a continuous 7-0 polypropylene suture conjoining the dissected arterial layers and the patch (Fig 3). The patch can be created with either a saphenous vein or autologous pericardium. In the presence of coronary intussusception (type C), the coronary artery is transected in a nondiseased zone and saphenous vein reconstruction of the vessel is performed with an end-to-end anastomosis (Fig 4). In general, for the left coronary artery, reconstruction is possible only if dissection does not go beyond the left main bifurcation. There are no precise limits for repair of the right coronary artery. However, too long a patch should be avoided because the excess length may result in kinking of the vessel. In the presence of extensive distal dissection, coronary bypass grafting is the only alternative to ostial reconstruction. Saphenous vein grafts are used, because thoracic artery bypass in emergency surgery for acute aortic dissection is not advisable. Polytetrafluoroethylene artificial grafts have never been used in our patients. None of the repaired coronary arteries was treated with a supplemental bypass. Table III summarizes our experience with these techniques.

Statistical methods. Univariate analyses were performed on the perioperative variables, relating them to operative mortality. In the case of continuous variables, a Student $t$ test was used. For the categoric variables, a Fisher exact test was used. SPSS application software version 10.0 (SPSS Inc, Chicago, Ill) was used for statistical analyses.

\section{Results}

Mortality. Overall hospital mortality was $20 \%$ (5 patients). Three patients could not be weaned from CPB. All these patients also had a preoperative stroke. The first one also had a preoperative anterolateral Qwave myocardial infarction. A type A lesion of the right coronary artery with malperfusion and a type $\mathrm{C}$ lesion of the left main trunk were present. She was the first patient of this series, and no coronary repair was attempted. She was treated with aortic root replacement and 3 saphenous vein grafts on the left anterior descending, right coronary, and obtuse marginal arteries. She could not be weaned from CPB because of severe biventricular failure associated with reperfusion arrhythmias and severe mitral regurgitation.

The second patient had a type $\mathrm{C}$ lesion of the right coronary artery and right ventricular infarction. He was treated with ascending aorta replacement and saphenous vein bypass grafting of the right coronary artery because of extensive dissection of the vessel. Both of these patients were treated without controlled reperfusion, and cardioplegic solution was administered only at the end of circulatory arrest.

The third patient was admitted after 2 episodes of cardiac arrest. He had signs of anterior myocardial infarction and inferior ischemia due to a type A lesion of a dominant right coronary artery, with malperfusion, and a type $\mathrm{C}$ lesion of the left main trunk. He was treated with a composite graft aortic root replacement, direct repair of the right ostium, and left main reconstruction with a short saphenous graft. The patient could not be weaned, after 6 hours of assistance, because of intractable ventricular fibrillation. Two $(8.3 \%)$ deaths occurred on postoperative days 4 and 10, respectively, as a result of multiorgan system failure caused by a low cardiac output syndrome.

One patient was treated without controlled reperfusion after preoperative left ventricular ischemia. Her 


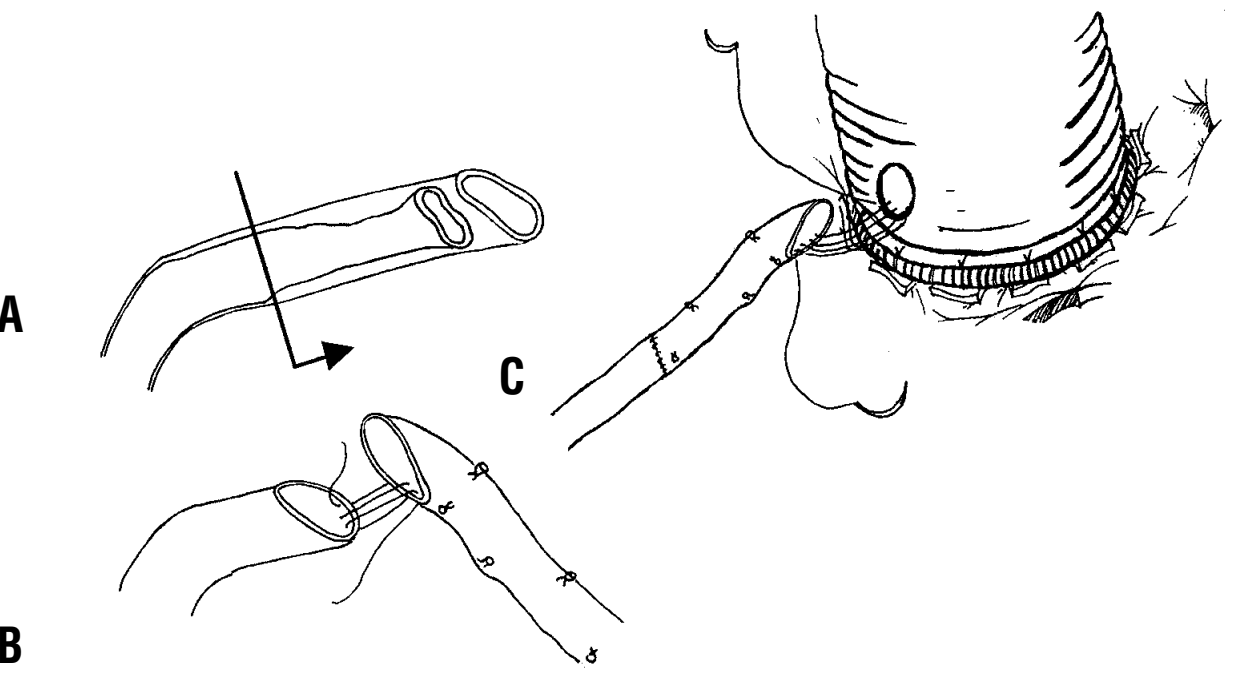

Fig 4. In the presence of coronary intussusception (type C), the coronary artery is transected in a nondiseased zone (A) and saphenous vein reconstruction of the vessel is performed with an end-to-end anastomosis (B). The repaired artery is then anastomosed to the aortic graft $(\mathbf{C})$.

type B lesion of the left coronary artery was treated with bypass grafting. She required maximal inotropic support to be weaned from the pump and displayed early postoperative renal and hepatic failure. The other patient was treated with ascending aorta replacement, repair of a type A lesion of the left coronary ostium, causing malperfusion, and short graft reconstruction of the right coronary type $\mathrm{C}$ lesion. Postoperative right ventricular failure was associated with a low cardiac output syndrome and multiorgan failure. Necropsy indicated perfect patency of both of the repaired arteries.

As indicated by univariate analysis (Table IV), significant perioperative patient variables correlated to operative mortality were as follows: preoperative ejection fraction less than $0.25(P<.001)$, preoperative CK-MB levels $(P<.001)$, presence of ventricular arrhythmias at the end of the procedure $(P<.001)$, persistence of mitral regurgitation at the end of the procedure $(P<.001)$, ejection fraction less than 0.25 at the end of the procedure $(P<.001)$, and postprocedure CK-MB levels $(P<.001)$. The presence of $\mathrm{Q}$ waves and the type of coronary lesion were weakly correlated to operative mortality.

Morbidity. All patients who survived the operation awoke from anesthesia with no evidence of a cerebrovascular accident. Postoperative hemorrhage necessitating reoperation developed in $2(8.3 \%)$ patients. Reoperation for late pericardial effusion was performed in $3(12.5 \%)$ patients, on postoperative days 7,9 , and 11. Ten $(41.6 \%)$ patients needed prolonged postoperative inotropic support for low cardiac output syndrome.
Postoperative atrial tachyarrhythmias were present in 12 $(50 \%)$ patients and ventricular arrhythmias in $6(25 \%)$. Two $(8.3 \%)$ patients underwent tracheotomy for prolonged ventilatory weaning. One $(4.5 \%)$ patient with preoperative renal insufficiency required long-term hemodialysis treatment. Continuous hemodiafiltration was used in $6(4.5 \%)$ patients for the relief of acute renal insufficiency.

The 19 patients who survived the operation had a mean intensive care unit stay of $6.1 \pm 2.6$ days, with a mean hospital stay of $15.1 \pm 5.1$ days.

Follow-up. The 19 patients who survived the operation were observed from 1 to 161 months (mean 48.5 months) after the operation. There were 4 late deaths at $11,24,29$, and 40 months, postoperatively. Of these, the cause of death in only 1 patient was related to cardiac problems (ventricular fibrillation during hemodialysis); the other 3 patients died of lung cancer, breast cancer, and a car accident, respectively. Three patients were uneventfully reoperated on for secondary aortic valve regurgitation. Fifteen patients are alive in New York Heart Association functional class I (4 patients), class II (6 patients), and class III (5 patients).

\section{Discussion}

This study presents our approach to coronary malperfusion resulting from retrograde dissection of the aortic root reaching the coronary ostia, developed over a 15year period. In addition, it suggests a classification scheme by which the problem may be more precisely studied. 
Table IV. Influence of perioperative risk factors on operative mortality: Univariate analysis

\begin{tabular}{|c|c|c|c|}
\hline \multirow[b]{3}{*}{ Risk factor } & \multicolumn{2}{|c|}{ Operative death } & \multirow[b]{3}{*}{$\mathrm{P}$ value } \\
\hline & $\operatorname{Yes}(n=5)$ & No $(n=19)$ & \\
\hline & $n$ & $n$ & \\
\hline Age (continuous variable) & - & - & .25 \\
\hline Sex: Female & $2(40 \%)$ & $8(42.1 \%)$ & .38 \\
\hline Renal insufficiency & $1(20 \%)$ & 0 & .2 \\
\hline COPD & 0 & $3(15.7 \%)$ & .47 \\
\hline Hypotension at admission & $5(100 \%)$ & $11(57.8 \%)$ & .10 \\
\hline RCA type A lesions & $3(60 \%)$ & $6(31.5 \%)$ & .26 \\
\hline RCA type B lesions & 0 & $8(42.1 \%)$ & .10 \\
\hline RCA type $\mathrm{C}$ lesions & $2(40 \%)$ & $1(5.2 \%)$ & .09 \\
\hline LCA type A lesions & $1(20 \%)$ & $2(10.5 \%)$ & .42 \\
\hline LCA type B lesions & $1(20 \%)$ & $3(15.7 \%)$ & .45 \\
\hline LCA type $\mathrm{C}$ lesions & $2(40 \%)$ & $4(21 \%)$ & .28 \\
\hline Preoperative MR & $3(60 \%)$ & $3(15.7 \%)$ & .07 \\
\hline Postoperative MR & $4(60 \%)$ & 0 & $<.001$ \\
\hline Cardiac tamponade & $1(20 \%)$ & $3(15.7 \%)$ & .45 \\
\hline Cardiac arrest—fibrillation & $2(40 \%)$ & $1(5.2 \%)$ & .09 \\
\hline Preoperative atrial arrhythmias & $3(60 \%)$ & $8(42.1 \%)$ & .30 \\
\hline Postoperative atrial arrhythmias & $3(60 \%)$ & $11(57.8 \%)$ & .38 \\
\hline Preoperative ventricular arrhythmias & $3(60 \%)$ & $4(21 \%)$ & .11 \\
\hline Postoperative ventricular arrhythmias & $5(100 \%)$ & $2(10.5 \%)$ & $<.001$ \\
\hline Preoperative $\mathrm{Q}$ waves & $5(100 \%)$ & $11(57.8 \%)$ & .10 \\
\hline Preoperative $\mathrm{EF}<0.25$ & $5(100 \%)$ & $1(5.2 \%)$ & $<.001$ \\
\hline Postoperative $\mathrm{EF}<0.25$ & $5(100 \%)$ & 0 & $<.001$ \\
\hline Crystalloid cardioplegia & $3(60 \%)$ & $3(15.7 \%)$ & .07 \\
\hline Preoperative CK-MB levels (continuous variable) & - & - & $<.001$ \\
\hline Postoperative CK-MB levels (continuous variable) & - & - & $<.001$ \\
\hline
\end{tabular}

$C O P D$, Chronic obstructive pulmonary disease; $R C A$, right coronary artery; $L C A$, left coronary artery; $M R$, mitral regurgitation; $E F$, ejection fraction; $C K-M B$, creatine kinase MB.

Our approach is based on the concept that repair of torn coronary arteries is preferable to coronary bypass grafting. The rationale for this attitude resides in both technical and hemodynamic considerations. The advantages are as follows: (1) Reconstruction of the coronary ostia is anatomic, and it avoids extensive revascularization on vessels whose diameter, importance, and status are often undetermined; (2) it avoids ligature of the coronary ostium and the consequent complete graft-dependent perfusion of large territories of the myocardium; and (3) it provides antegrade flow in the coronary tree, thus avoiding the risk of competitive flows ${ }^{5}$ and of coronary redissection. The latter point is of particular importance to us. In 2 cases of right coronary artery reconstruction for type $\mathrm{B}$ lesions, we have found distal re-entries some millimeters distal to the ostium. If we had performed bypass grafting, we could not exclude that a local re-entry would have determined a redissection along the artery, beyond the site of anastomosis, favored by the pressure on the proximal stump.
Development of the technique was stimulated by the dismal results with coronary artery bypass grafting observed at the beginning of our experience (Table V). At that time we regarded the ligature of the coronary ostia and the diversion of blood through the bypass grafts as causes of failure. Subsequent developments in myocardial protection and the clinical application of the concepts of myocardial resuscitation ${ }^{6,7}$ greatly improved the results in these operations without diverting our efforts to ensure anatomic reconstruction of the coronary tree. The results obtained with this approach demonstrate that coronary repair is feasible in most cases (Tables III and V) and that the integrated approach of coronary reconstruction and aggressive myocardial management provides encouraging results (Table V).

Although the described techniques may appear cumbersome and time consuming, patch repair and short graft reconstruction are not technically demanding when optimal visualization is obtained, in particular for the left main coronary artery. The coronary arteries are exposed 
Table V. Differences in operative techniques and mortality during the period of the study

\begin{tabular}{lcccc}
\hline $\begin{array}{l}\text { Year of } \\
\text { operation }\end{array}$ & $\begin{array}{c}\text { No. of } \\
\text { patients }\end{array}$ & $\begin{array}{c}\text { Coronary lesions treated } \\
\text { with CABG, } n(\%)\end{array}$ & $\begin{array}{c}\text { Blood cardioplegia and } \\
\text { controlled reperfusion }\end{array}$ & $\begin{array}{c}\text { Hospital } \\
\text { mortality, } n(\%)\end{array}$ \\
\hline $1986-1988$ & 6 & $4 / 9(44 \%)$ & No & $3 / 6(50 \%)$ \\
1989 to present & 18 & $1 / 24(4 \%)$ & Yes & $2 / 18(11 \%)$ \\
\hline
\end{tabular}

for reconstruction during the cooling period, thus hastening the subsequent repair. Finally, anatomic reconstruction makes reoperation in these patients easy: reimplantation of repaired coronary arteries poses no technical difficulty and the risk of graft injury is negligible.

Composite graft replacement of the aortic root for reimplantation of the restored coronary orifices has been extensively applied in this series, mostly because of the high incidence of bicuspid aortic valves (10 patients). We now prefer to perform aortic valve-sparing techniques when possible. The results with the Yacoub technique in 4 patients are encouraging even though 1 patient required reoperation.

Distal repair with hemiarch replacement is our standard approach in patients with aortic dissection; the technique was used in the last 20 patients of this series without particular complications.

In recent years, progress in noninvasive diagnostic techniques, in particular transesophageal echocardiography, allows aortic dissection to be diagnosed accurately and the extension of the dissection, the presence and the degree of valvular regurgitation, and the entity of myocardial impairment to be evaluated precisely.

If angiography is no longer needed to establish or confirm the diagnosis of acute dissection, it still represents the gold standard to evaluate the coronary anatomy and to discriminate acute CAD caused by ostial involvement from chronic CAD. Nevertheless, the role of coronary angiography before emergency repair of acute aortic dissection is controversial. A recent article by Penn and colleagues ${ }^{8}$ indicates that determination of coronary anatomy has no impact on survival. Rizzo and coworkers $^{9}$ found angiography to be associated with increased mortality owing to aortic rupture during the delay to surgical intervention.

We have found an intrinsic difficulty in performing coronary angiography in patients with coronary malperfusion because of their hemodynamic instability. Moreover, the visualization of the coronary tree may be suboptimal because of flow obstruction, as we observed in 3 of the 8 patients who have undergone preoperative coronary angiography. Nevertheless, we are convinced of the necessity to obtain information about coronary anatomy in patients with aortic dissection and, in particular, in those with coronary malperfusion. Intraoperative coronary angiography is now possible and its routine application in patients with aortic dissection will allow these difficulties to be overcome.

Interestingly, in our series none of the patients had evidence of occlusive CAD: this finding is in variance with the results of studies about CAD in patients with type A aortic dissection, which reported a prevalence between $22 \%$ and $35 \% .^{10,11}$ To explain this circumstance, we hypothesized that chronic CAD, in particular at the origin of the coronary artery, could somehow protect from extensive dissection.

In the absence of coronary angiography, electrocardiography maintains its importance in topographic evaluation of malperfused myocardium. We observed that preoperatively the location of Q waves accurately correlated with wall motion abnormalities and with the actual coronary involvement, thus giving precious information about the degree of functional coronary impairment. Postoperatively, the correlation between topography of $\mathrm{Q}$ waves and wall motion abnormalities was less specific, suggesting that electrocardiographic signs may persist also in areas of rescued myocardium.

Type $\mathrm{B}$ and $\mathrm{C}$ lesions were accompanied by the most serious clinical conditions, and Q waves accurately reflected the severity of coronary malperfusion: all 16 patients with preoperative $\mathrm{Q}$ waves had at least one type $\mathrm{B}$ or $\mathrm{C}$ lesion. The survival of 5 of the 9 patients with type $\mathrm{C}$ lesions and of 11 of the 12 patients with type $\mathrm{B}$ lesions, as well as the weak correlation between mortality and the presence of preoperative $\mathrm{Q}$ waves $(P=.10)$, illustrates that the operation effectively reversed severe degrees of malperfusion (Table IV).

In summary, aggressive myocardial resuscitation and early operation are the key factors in the management of these patients. The technical feasibility of coronary repair and its relative safety represent an alternative to bypass grafting, guarantee anatomic reconstruction, and overcome the difficulties of revascularization when a coronary angiogram cannot be obtained.

Received for publication July 12, 2000; revisions requested Sept 7, 2000; revisions received Oct 6, 2000; accepted for publication Oct 26, 2000. 
Address for reprints: Eugenio Neri, MD, Istituto di Chirurgia Cardiovascolare Universita' agli Studi di Siena, Policlinico le Scotte, Viale M. Bracci, 53100 Siena, Italy (Email: euxneri@tin.it nerie@unisi.it).

\section{REFERENCES}

1. Hirst AE, Jones VJ, Kime SW. Dissecting aneurysm of the aorta: a review of 505 cases. Medicine 1958;37:217-79.

2. Borst HG. In: Borst HG, Heinemann MK, Stone CD, editors. Surgical treatment of aortic dissection. 1st ed. New York: Churchill Livingstone; 1996. p. 249-64.

3. Butler J, Davies AH, Westaby S. Streptokinase in acute aortic dissection. BMJ 1990 24;300:517-9.

4. Melchior T, Hallam D, Johansen BE. Aortic dissection in the thrombolytic era: early recognition and optimal management is a prerequisite for increased survival. Int J Cardiol 1993;42:1-6.

5. Dion R, Verhelst R, Matta A, Rousseau M, Goenen M, Chalant C. Surgical angioplasty of the left main coronary artery. J Thorac Cardiovasc Surg 1990;99:241-9.
6. Buckberg GD. Studies of controlled reperfusion after ischemia. I. When is cardiac muscle damaged irreversibly? J Thorac Cardiovasc Surg 1986;92:483-7.

7. Beyersdorf F, Sarai K, Maul FD, Wendt T, Satter P, Buckberg GD. Immediate functional benefits after controlled reperfusion during surgical revascularization for acute coronary occlusion. J Thorac Cardiovasc Surg 1991;102:856-66.

8. Penn MS, Smedira N, Lytle B, Brener SJ. Does coronary angiography before emergency aortic surgery affect in-hospital mortality? J Am Coll Cardiol 2000;35:889-94.

9. Rizzo RJ, Aranki SF, Aklog L, Couper GS, Adams DH, Collins $\mathrm{JJ} \mathrm{Jr}$, et al. Rapid noninvasive diagnosis and surgical repair of acute ascending aortic dissection: improved survival with less angiography. J Thorac Cardiovasc Surg 1994;108:567-75.

10. Larson E, Edwards W. Risk factors for aortic dissection: a necropsy study of 161 cases. Am J Cardiol 1984;53:849-55.

11. Creswell L, Jouchoukos N, Cox J, Rosenbloom M. Coronary artery disease in patients with type A aortic dissection. Ann Thorac Surg 1995;59:585-90.

\section{Bound volumes available to subscribers}

Bound volumes of The Journal of Thoracic and Cardiovascular Surgery are available to subscribers (only) for the 2001 issues from the Publisher, at a cost of $\$ 134.00$ for domestic, $\$ 165.85$ for Canadian, and $\$ 155.00$ for international subscribers for Vol 121 (January-June) and Vol 122 (July-December). Shipping charges are included. Each bound volume contains a subject and author index and all advertising is removed. Copies are shipped within 60 days after publication of the last issue of the volume. The binding is durable buckram with the Journal name, volume number, and year stamped in gold on the spine. Payment must accompany all orders. Contact Mosby, Subscription Customer Service, 6277 Sea Harbor Dr, Orlando, FL 32887,USA; phone 800-654-2452 or 407-345-4000.

Subscriptions must be in force to qualify. Bound volumes are not available in place of a regular Journal subscription. 